\title{
O CONCEITO DE CAMPO: POLISSEMIA NOS MANUAIS, SIGNIFICADOS NA FÍSICA DO PASSADO E DA ATUALIDADE*
}

\section{The field concept: multiple character within textbooks, meanings in past and present Physics}

\author{
Sonia Krapas ${ }^{1}$ \\ Marcos Corrêa da Silva ${ }^{2}$
}

\begin{abstract}
Resumo: Este trabalho objetiva evidenciar o caráter polissêmico do termo campo em livros didáticos de ensino médio; estudar seus significados em textos históricos; mostrar que a polissemia desse conceito tem raízes nos significados atribuídos tanto no passado como na atualidade. Sob a luz do marco teórico atual da física e de textos históricos, analisaram-se sete manuais de ensino médio em circulação que, quando oportuno, foram cotejados com livros didáticos universitários e manuais antigos. Destacam-se as seguintes atribuições de significado, algumas na forma de definições explícitas, outras implicitamente apresentadas: é espaço; é um vetor; propaga-se, é suporte para a propagação de energia; é curvatura do espaço; armazena energia; interage com partículas, media a interação entre partículas; preenche o espaço. A polissemia pode ser creditada, em parte, à forma velada de introdução da física moderna nos manuais. Faz-se uma tentativa de compreender essa introdução segundo a perspectiva da transposição didática de Chevallard.
\end{abstract}

Palavras-chave: Campo. Polissemia. Livros didáticos. História da ciência.

\begin{abstract}
This paper aims at: evidencing the polissemic character of the term field within High School textbooks; studying its meanings in historical texts; showing that the roots of such meaning variety are found in both past and present days. Considering as reference the current theoretical mark of Physics and historical texts, seven secondary education manuals were analyzed. When appropriate, such manuals were compared to those found in old education and undergraduate textbooks. Meaning differences could be pointed out, both implicitly and explicitly. Such meanings are: space; vector; something that propagates itself and supports energy propagation; space curvature; energy resevoir; it interacts with particles and mediates their interaction; it fills space. Partly, this polissemy can be credited to the concealed form of introducing Modern Physics in manuals. An attempt is made to understand this introduction in face of Chevallard's didactic transposition.
\end{abstract}

Key words: Field. Polissemy. Didactic books. History of science.

*Trabalho originalmente apresentado no V Encontro Nacional de Pesquisa em Educação em Ciências, Bauru, SP, 2005.

${ }^{1}$ Doutor em Educação; docente, Departamento de Física, Universidade Federal Fluminense, UFF. Niterói, RJ. <sonia@if.uff.br>

${ }^{2}$ Mestre em Educação; professor de Física do Ensino Médio, Colégio Plínio Leite, Niterói, e Centro Educacional Espaço Integrado. Rio de Janeiro, RJ. <marcos.fismarc@gmail.com>

${ }^{1}$ Av. Quintino Bocaiuva, 187/401

Niterói, RJ

$24.360-022$ 
Krapas, S.; Da Silva, M. C.

\section{Introdução}

Em nossa experiência como professores de Física, pudemos constatar que muitos fenômenos são explicados pelos alunos com o auxílio do conceito de campo: os corpos caem por causa do campo gravitacional da Terra, pregos são atraídos por um ímã por causa de seu campo magnético... Ainda que essas explicações não estejam incorretas, podem estar indicando uma aprendizagem superficial, uma "naturalização" do conceito, o que fica evidenciado pelo uso do mesmo tipo de explicação para fenômenos mais complicados, como o funcionamento de um motor elétrico simples ou o comportamento de um material ferromagnético dentro de um solenóide (KRAPAS et al., 2005). Parece que o termo campo encerra - tanto no sentido de guardar em lugar que se fecha, como no sentido de terminar - a explicação. Podemos dizer que o conceito de campo encontra-se encapsulado.

Por que esse conceito tão atraente é, ao mesmo tempo, tão mal compreendido pelos estudantes (DOMÍNGUEZ e MOREIRA, 1988)? Perante esse panorama, recordamos a sugestão de Galili (1995): pode ser valioso considerar a controvérsia histórica ação mediada versus ação à distância para justificar a introdução do conceito de campo. Também é valioso considerá-la para repensar o ensino das interações físicas (ASSIS, 2006; GARDELLI, 2004; ARONS, 1997). Em 2001, Furió e Guisasola avaliaram proposta de ensino baseada nessa controvérsia e, como Pocovi e Finley (2003) e Furió e Guisasola (1997), entendemos importante investigar como o livro didático - principal, senão única, fonte de consulta de estudantes e professores - apropria-se dela. A partir da análise de três livros do Ensino Médio (KRAPAS e DA SILVA, 2004), constamos que, em geral, a controvérsia não é citada e, quando aparece, é relegada a um papel secundário, já que se encontra fora do corpo do texto, não sendo explorada didaticamente na introdução do conceito de campo.

Neste trabalho levantamos a suspeita de que uma das razões das dificuldades dos estudantes para a aprendizagem do conceito de campo reside em seu caráter polissêmico, que pode ser creditado a suas origens na história da ciência - encontrada no reduto da citada controvérsia - como também a uma certa "contaminação" do sentido "relativístico" sobre o sentido "clássico" de campo. Temos como objetivos evidenciar esse caráter polissêmico em livros didáticos do Ensino Médio; estudar os significados atribuídos ao termo campo em textos históricos; e mostrar que a polissemia desse conceito tem raízes nos significados a ele atribuídos tanto no passado como na atualidade.

\section{Livros didáticos e textos históricos}

Para analisar os significados atribuídos pelos manuais ao termo campo, além do marco teórico atual da Física tomamos como referência textos históricos de cientistas que se apropriaram de tal termo. Uma ressalva: o conceito de campo é geralmente atribuído a Faraday, possivelmente por suas contribuições decisivas para o acirramento da controvérsia acerca das explicações para as interações físicas, as quais têm suas origens na antigüidade grega (ABRANTES, 1998) e que são notáveis no período que vai de Gilbert a Einstein (GARDELLI, 2004). Porém, como estamos interessados nos significados atribuídos ao termo, nosso estudo 
não inclui Faraday, uma vez que o termo não aparece em sua obra ${ }^{3}$. Ainda que Lorentz tenha sido apreciado, fixamo-nos, principalmente, nos escritos originais de Maxwell, um dos pioneiros no uso desse termo ${ }^{4}$. Em On Faraday's lines of force, On physical lines of force e $A$ dynamical theory of electromagnetic field a busca foi feita no texto integral; em $A$ Treatise on electricity and magnetism $\mathrm{e}$ Theory of Electrons (este último de Lorentz), a busca se fixou nos tópicos correlatos à definição do termo. Procedemos à análise dos significados tendo como foco, além de definições explícitas, expressões utilizadas pelos autores.

Definições e expressões também foram buscadas nos livros didáticos, em capítulos/ tópicos nos quais se espera que apareçam: campo gravitacional/gravitação, campo elétrico e campo magnético. Também foram lidos, na íntegra, textos sobre a teoria da relatividade que já começam a aparecer nos manuais brasileiros por conta das demandas dos Parâmetros Curriculares Nacionais (PCNs), estes localizados em box, tópicos especiais ou capítulos.

Neste estudo, expandimos a amostra de livros em relação ao trabalho anterior (KRAPAS e DA SILVA, 2004) de três para sete títulos, usando como critério a avaliação realizada no âmbito do Programa Nacional do Livro para o Ensino Médio - PNLEM (BRASIL, 2006)5. Entre os dois títulos de Sampaio e Calçada (2001) optamos pelo de três volumes (o outro título era de volume único), Universo da Física, por considerá-lo mais completo. Pelo mesmo motivo, substituímos o livro de Gaspar de volume único, pelo de três volumes, Física (GASPAR, 2000a, 2000b), apesar de esta versão não ter sido submetida à avaliação no PNLEM. Assim, dos seis títulos aprovados pelo PNLEM, ficamos ainda com Física de Máximo e Alvarenga (2002) e Física de Gonçalves e Toscano (2003). Incluímos, ainda, a coleção Física de Guimarães e Fonte Boa (2001a, 2001b), que, apesar de não ter sido avaliada pelo PNLEM, é vista pela comunidade com equivalente padrão de qualidade ${ }^{6}$. Além desses, analisamos um livro estrangeiro com tradução para o português pela editora Artmed: o título - Física conceitual (Hewitt, 2002) - dá uma indicação do seu caráter inovador ${ }^{7}$. O livro de Ramalho, Nicolau e Toledo (1998), Os fundamentos da fisica, foi escolhido por se tratar de sucesso editorial há décadas.

\footnotetext{
${ }^{3}$ Nancy Nersessian, possivelmente por conhecer tal fato (e não compartilhando de nossos objetivos), faz questão de tornar explicícita uma definição mais ampla do termo: "o conceito de campo envolve a noção de que algum processo físico toma lugar na região que envolve os corpos em questão" (NERSESSIAN, 1984, p. 34). Com isso, a autora fica à vontade ao incluir Faraday em seu trabalho.

${ }^{4}$ Em The Oxford English Dictionary (1961), além de Maxwell encontram-se referências a Tyndall (1863) e a Watson e Burbury (1884), autores que, como Maxwell, utilizam o verbete campo com o significado de "área de operação ou observação".

${ }^{5}$ Física - Ciência e Tecnologia, volume 1, 2 e 3, de Torres e Penteado, foi publicado pela Editora Moderna em 3 volumes apenas para se submeter à avaliação. Por estar indisponível para a venda, não pôde fazer parte de nossa amostra de livros.

${ }^{6}$ No último Simpósio Nacional de Ensino de Física, um de seus autores compunha, juntamente com Beatriz Alvarenga e Alberto Gaspar, mesa redonda com o título Análise de livros didáticos de Física para o Ensino Médio.

${ }^{7}$ Logo nas primeiras páginas, o autor avisa aos estudantes: "Você verá a estrutura matemática da Física em várias equações, mas as verá como guias do pensamento, mais do que como receitas para realizar cálculos" (HEWITT, 2002).
} 
Krapas, S.; Da Silva, M. C.

Livros introdutórios de física de nível universitário são citados como contraponto: Física, de Tipler (1984), e Fundamentos de Física, de Halliday e Resnick (1991), por se tratarem de livros amplamente adotados nas disciplinas de Física básica no Brasil e em outros países; Curso de Física Básica, de Nussenzveig (1997 e 1992), e Física, de Chaves (2001), por se tratarem de obras nacionais de reconhecida qualidade. Sem pretender explicitar os diversos processos de transposição didática pelos quais o conceito de campo passou, mas com a intenção de mostrar certas filiações, manuais antigos também são citados. Com exceção do importante livro de Ganot (1984), traduzido do francês para diversos idiomas, e Gouvêa (s.d.), também adotado no Colégio Pedro II, os demais livros não foram submetidos a outros critérios que não o da acessibilidade.

\section{Análise e interpretação dos resultados}

Da análise dos livros didáticos do Ensino Médio detalhamos, nos itens que seguem, atribuições de significado para o termo campo. Em definições explícitas: campo é espaço, campo é vetor, são analisadas essas definições em comparação com expressões utilizadas pelos autores. Algumas delas, por introduzir novidades em relação às definições explicitadas, são tratadas separadamente nos seguintes itens: campo como curvatura do espaço; campo armazena energia; campo interage com partículas, media a interaşão entre partículas; campo se propaga, é suporte para a propagaşão; campo preenche o espaço.

\section{Definições explícitas: campo é espaço, campo é um vetor}

Entre as definições que aparecem nos livros didáticos, vale destacar a distinção entre campo e vetor campo elétrico adotada por Gaspar (2000b, p. 34):

[...] o campo de temperaturas de uma sala é caracterizado pela grandeza temperatura, o campo de velocidades da corrente de um rio é caracterizado pela grandeza velocidade. Ninguém confunde campo de temperaturas com a grandeza temperatura, nem campo de velocidades com a grandeza velocidade. A diferença entre as duas coisas é óbvia. Mas com o campo elétrico essa confusão é freqüente, pois o campo elétrico costuma ser caracterizado pela grandeza campo elétrico. Para evitar essa confusão, vamos adotar neste livro uma diferenciação clara entre essas duas idéias. Chamaremos sempre de campo elétrico a região em que as partículas eletricamente carregadas sofrem a ação de força ou adquirem energia devido à sua carga elétrica, e vetor campo elétrico $\mathbf{E}$ a grandeza que permite determinar, em cada ponto, a intensidade da força que atua sobre a carga aí colocada.

Campo é espaço e vetor campo é definido algebricamente como uma grandeza aparentada da força. De qualquer forma, é fácil entender a confusão apontada por Gaspar: uma coisa é 
O conceito de campo: polissemia nos manuais, significados ...

associar um campo a grandezas como velocidade e temperatura; outra é associar um campo a uma grandeza denominada campo. Em manuais antigos (CROWTHER, 1921; POYNTING e THOMSON, 1914) também encontramos tal distinção: campo é região e intensidade de campo é a grandeza física. Diferentemente, para Sampaio e Calçada (2001, p. 227), "campo não é uma região”. Nos outros manuais atuais não há ocorrência de tal alerta para essa distinção.

Expressões como "campo gravitacional em torno da Terra" (GUIMARÃES e FONTE BOA, 2001b, p. 117) ficam ambíguas. Já na definição não algébrica "se numa região do espaço um corpo sofre a ação de força, nessa região existe um campo cuja natureza depende da causa que origina a força ou interação" (GASPAR, 2000a, p. 269, grifo nosso) pode-se inferir que o significado de campo não é espaço. Além disso, nada é possível de se afirmar. Em Guimarães e Fonte Boa (2001b), Máximo e Alvarenga (2002) e Nussenzveig (1992) também encontramos a mesma definição. A ocorrência desse tipo de definição - tão pouco esclarecedora - possivelmente tem sua origem em velhos manuais (ATTWOOD, 1941; HARNWELL, 1938).

Inequívoca é a definição algébrica de campo, comum a todos os livros estudados: "A intensidade do campo elétrico em $\mathrm{P}_{1}$ será, por definição, dada pela expressão: $\mathrm{E}=\underline{\mathrm{F}}$ ” (MÁXIMO e ALVARENGA, 2002, p. 56).

A dualidade de significado apontada por Gaspar (2000b) não existe na formulação de Maxwell. A grandeza que hoje denominamos campo é batizada por Maxwell Intensidade Resultante Eletromotri\%:

Se um corpo eletrificado é colocado em qualquer parte do campo elétrico ele irá, em geral, produzir um sensível distúrbio na eletrificação dos outros corpos. Mas se o corpo é muito pequeno, e sua carga também muito pequena, a eletrificação dos outros corpos não será sensivelmente perturbada, e nós podemos considerar a posição do corpo como determinada por seu centro de massa. A força agindo no corpo será então proporcional à sua carga, e será invertida quando a carga é invertida.

Seja 'e' a carga do corpo, e ' $\mathrm{F}$ ' a força agindo no corpo numa certa direção, então quando 'e' é muito pequeno 'F' é proporcional a 'e', ou: $\mathrm{F}=\mathrm{Re}$, onde ' $R$ ' depende da distribuição de eletricidade nos outros corpos do campo. [...] Nós podemos chamar 'R' de Intensidade Resultante Eletromotriz num dado ponto do campo. (MAXWELL, 1954a, p. 48)

O termo campo aparece nos três primeiros trabalhos sobre o eletromagnetismo geralmente com o significado de espaço ${ }^{8}$ - "condutor fechado num campo magnético" (MAXWELL, 1952a, p. 187) e "um ímã é colocado naquela parte do campo" (MAXWELL,

\footnotetext{
${ }^{8}$ Vale notar que a noção de espaço em Maxwell é newtoniana, portanto diferencia-se completamente da noção na Física relativística geral.
} 
1952b, p. 452) -, sendo que uma definição explícita aparece somente no terceiro artigo (em cujo título aparece a palavra campo): "O campo eletromagnético é aquela parte do espaço que contém e envolve corpos em condições elétricas ou magnéticas" (MAXWELL, 1952c, p. 527). Em seu famoso Tratado, Maxwell mantém a definição: "O Campo Elétrico é a porção do espaço na vizinhança dos corpos eletrificados, considerado com referência aos fenômenos elétricos" (MAXWELL, 1954a, p. 47). Herdeiro de Faraday, Maxwell era um opositor da ação à distância e favorável à ação mediada, posição que justifica a ênfase no termo campo, usado para explicitar a importância do espaço entre os corpos em interação. Nas palavras de Maxwell (1952c, p. 527): "A teoria que eu proponho pode, portanto, ser chamada de uma teoria do Campo Eletromagnético, porque trata do espaço na vizinhança dos corpos elétricos ou magnéticos".

A esse espaço Maxwell atribui propriedades. É constituído de um meio que pode ser magnetizável: "real magnetização do campo" (MAXWELL, 1952c, p. 553); que pode ser isolante: "campo não condutor" (p. 535); e que suporta a propagação de uma onda: "perturbação magnética propagada através de um campo" (p. 535). Além disso, pode ser representado por meio de linhas de força (representação que se mantém em todos os livros didáticos estudados): "Sejam as linhas paralelas [...] na figura 1 representando um campo de força magnética" (MAXWELL, 1952b, p. 459).

Há ainda, em Maxwell - especialmente em seu primeiro trabalho, expressões tais como "campo magnético constante" (1952a, p. 218), "campo magnético de intensidade variável" (p. 214), "uma parte muito fraca do campo magnético" (p. 553) e "variação com o tempo do campo magnético" (1954a, p. 241). Levando-se em conta o linguajar atual, essas expressões podem levar à idéia de que campo é uma grandeza que tem intensidade. Expressões como "campo uniforme de força magnética" (MAXWELL, 1952a, p. 222) podem esclarecer: campo é espaço a cujos pontos se associa uma força, que pode ser constante ou variável. Além disso, não é possível localizar uma definição de tal grandeza. Expressão como "Seja $I$ a intensidade magnética não perturbada do campo" define a grandeza intensidade magnética $I$, que pode também ser associada a cada ponto do campo (espaço).

Em seu importante trabalho The Theory of Electrons, de 1915, Lorentz escreve as "fórmulas do campo eletromagnético" hoje conhecidas como equações de Maxwell, sem as grandezas campo elétrico e campo magnético, mas com os vetores $\mathbf{d}$ e $\mathbf{h}$, respectivamente força elétrica e força magnética. Campo é explicitamente definido com o significado de espaço: "Um espaço que se associa a cada um de seus pontos, um vetor $\mathbf{A}$ que tem uma direção definida e uma magnitude definida pode ser chamado de um campo vetorial" (LORENTZ, 1952, p. 4, grifo nosso). Portanto, expressões como "campo h" (p. 15) têm esse significado com respeito ao vetor força magnética $\mathbf{h}$.

Expressões tais como as utilizadas por Maxwell e Lorentz podem explicar o fato de que, em algum momento do processo de transposição didática ${ }^{9}$, fosse atribuída uma grandeza física ao termo campo, tal como conhecemos hoje.

${ }^{9}$ É interessante observar que em seu famoso artigo de 1905, Einstein (1971) ainda escreve as equações de Maxwell com as mesmas grandezas usadas por Lorentz, enquanto em livro didático de 1914, ao campo elétrico já se associa uma grandeza algebricamente definida (POYNTING e THOMSON, 1914). 
O conceito de campo: polissemia nos manuais, significados ...

\section{Campo como curvatura do espaço}

Ainda que colocada fora do corpo do texto ou em capítulo próprio, referência à Relatividade Geral contribui para a polissemia: "Vem Einstein e cria uma outra teoria, na qual o campo gravitacional de um astro é 'explicado' pela propriedade que a matéria possui, de curvar o espaço" (GUIMARÃES e FONTE BOA, 2001a, p. 252); "um campo gravitacional é uma dobra no espaço-tempo" (HEWITT, 2002, p. 630).

\section{Campo armazena energia}

Em Hewitt encontramos a seguinte passagem: "Aprendemos que o campo elétrico é uma espécie de armazém de estocagem de energia" (2002, p. 381). Em livros como o de Halliday e Resnick (1991, p. 99) também se encontra tal idéia: "energia armazenada no campo". Afirmações desse tipo podem causar certa confusão na mente do aprendiz, mesmo quando aluno universitário. Se considerarmos sua definição algébrica, surge a dúvida: como pode a grandeza energia estar armazenada numa outra grandeza?

Como já evidenciado, para Maxwell campo é espaço, e uma das propriedades desse espaço é armazenar energia:

A única questão é: onde ela [a energia nos fenômenos eletromagnéticos] reside? Nas velhas teorias ela reside nos corpos elétricos, circuitos condutores, e imãs, na forma de uma quantidade desconhecida chamada energia potencial, ou poder de produzir certos efeitos a uma distância. Em nossa teoria ela reside no campo eletromagnético, no espaço que rodeia os corpos elétricos e magnéticos, tanto quanto nesses próprios corpos [...] (MAXWELL, 1952c, p. 564, grifo nosso)

Essa questão, crucial para Maxwell, é também abordada por Chaves, que argumenta:

É natural se questionar onde está localizada a energia potencial elétrica de uma carga ou de um sistema de cargas. O conceito de energia potencial [...] parece abstrato. Toma-se uma força, faz-se a sua integração em uma trajetória qualquer entre dois pontos para se calcular um trabalho e diz-se que tal trabalho fica armazenado na forma de energia potencial. Tudo isso soa como mera matemática. Pergunta-se: onde fica armazenada a energia potencial? (CHAVES, 2001, p. 23)

A impressão que se tem é que, tal como em Maxwell, o significado atribuído por Chaves ao termo campo é espaço ${ }^{10}$ :

\footnotetext{
${ }^{10} \mathrm{Na}$ verdade, o significado, que será detalhado mais adiante, é outro. Isso porque há uma diferença entre as duas situações: em Maxwell (1952c) é estática, enquanto em Chaves (2001) a situação é dinâmica.
} 
Krapas, S.; Da Silva, M. C.

A evidência experimental acumulada mostra, sem margem para dúvidas, que a energia potencial elétrica se situa no campo elétrico. Aliás, no caso mais geral, nos campos elétrico e magnético. A radiação eletromagnética demonstra isso. Basta você considerar a energia que vem através da luz solar ou o processo pelo qual um forno de microondas aquece um copo de água para se convencer de que a energia eletromagnética é algo que pode se situar no espaço e se propagar através dele. (CHAVES, 2001, p. 23-24, grifos nossos)

Mas, para o aprendiz, surge outra dúvida: se campo é espaço, como pode a energia estar armazenada no espaço, espaço este desprovido de matéria? Energia não é algo que se associa a uma onda ou a uma partícula?

Para Maxwell isso não constituía um problema, uma vez que, partidário da ação contígua - em oposição à ação à distância - o espaço era preenchido pelo éter. Talvez por suspeitar que essa idéia não seja muito palatável, certos autores chegam a fazer afirmações menos positivas: "podemos pensar na energia como estando armazenada no campo" (NUSSENZVEIG, 1997, p. 81); "É conveniente imaginar que a energia está armazenada no campo elétrico" (TIPLER, 1984, p. 671); "A energia potencial de um capacitor carregado pode ser vista como se estivesse armazenada no campo elétrico entre as placas" (HALLIDAY e RESNICK, 1991, p. 81).

De qualquer forma, fica outra pergunta: como se pode falar em armazenamento de energia no campo no caso de interações eletrostáticas, caso em que não há emissão de ondas eletromagnéticas próprias da interação entre partículas em situação dinâmica? Essa questão será tratada em detalhe mais adiante.

\section{Campo interage com partículas, media a interação entre elas}

Outra fonte de incompreensão pode advir de expressões - surpreendentemente comuns nos livros do Ensino Médio (quadro 1) - como "O campo magnético terrestre [...] interage com o vento solar - partículas carregadas oriundas do Sol ${ }^{11}$ ” (GASPAR, 2000b, p. 181), expressão que também encontramos em antigos manuais: "uma carga [...] experimentaria uma força mecânica devida ao campo" (CROWTHER, 1921, p. 415). Expressões desse tipo advêm do entendimento de que campo é um agente intermediário nas interações e deixam as questões: como pode o campo, uma grandeza aparentada da força, agir sobre uma partícula? Como o campo age sobre uma partícula? Essa ação é típica de uma partícula ou de uma onda?

Máximo e Alvarenga usam campo com esse sentido: "a força elétrica que atua sobre q é devida à ação do campo elétrico e não à ação direta de Q sobre q." (2002, p. 55). Gaspar (2000b)

\footnotetext{
${ }^{11}$ Vale notar a diferença entre a exposição de Gaspar e a de Guimarães e Fonte Boa (2001, p. 171), menos problemática para o aprendiz: "o campo magnético da Terra também é modificado pelo vento solar, formado por partículas carregadas que são permanentemente expelidas pelo sol. Essas cargas em movimento geram um campo magnético que, superpondo-se ao campo intrínseco da Terra, faz com que o campo resultante seja diferente daquele produzido por um dipolo magnético".
} 
O conceito de campo: polissemia nos manuais, significados ...

e Sampaio e Calçada (2001) também o fazem. Mas Gonçalves e Toscano deixam a mediação explícita: "essa interação se manifesta por meio da ação da força magnética entre eles, e o campo magnético é o mediador dessa interação" (2003, p. 356). O mesmo se dá em Ramalho, Nicolay e Toledo (1998) e em Guimarães e Fonte Boa que, num box denominado História, escrevem:

O conceito de campo está intimamente relacionado a uma mudança radical no modo de encarar as interações entre os corpos. Elas não são mais vistas como uma ação à distância, direta e instantânea, entre duas massas, dois imãs ou duas cargas elétricas: há um 'agente intermediário' nas interações, e esse agente é o campo. (GUIMARÃES e FONTE BOA, 2001b, p. 118, grifo nosso)

Enquanto nos outros autores essa concepção aparece implicitamente, fora do corpo do texto ou com pouca ênfase, em Hewitt (2002) ela aparece como fundadora do conceito:

A Terra e a Lua atraem-se mutuamente. Isso é uma ação à distância, porque a Terra e a Lua interagem mesmo quando não estão em contato. Podemos colocar isso de outra maneira: podemos conceber a Lua como estando interagindo com o campo gravitacional da Terra. (p. 165, grifo nosso)

Podemos pensar em qualquer outro corpo massivo como estando em interação com o campo, e não diretamente com o corpo massivo que o produz. (p. 380, grifo nosso)

Assim como Guimarães e Fonte Boa, Hewitt associa essa mediação à dicotomia ação contígua versus ação à distância, mas, diferentemente deles, não há indicação de que essa dicotomia é histórica: "mudança radical no modo de encarar as interações". Típica no ensino de Física avançada, esta abordagem didática é assaz inovadora para o Ensino Médio: estudar as interações físicas como uma ação mediada pelo campo, com a introdução da dicotomia ação contígua versus ação à distância, mas sem localizá-la no reduto de uma controvérsia histórica (DA SILVA e KRAPAS, 2007). Para os defensores da introdução da história da ciência no ensino, essa abordagem didática tem chance de não ser bem sucedida, dada a importância dos meandros da história desse conceito para se entender seu status no âmbito da Física atual (GARDELLI, 2004; ABRANTES, 1998; CUSHING, 1998; NERSESSIAN, 1984; BERKSON, 1981; WHIT'TAKER, 1958).

De forma breve, pode-se dizer que a controvérsia referida acima nasce quando Newton introduz ação à distância, recrudesce com as críticas de Faraday a essa idéia e prossegue com Maxwell que, diferentemente de Faraday que tinha dúvidas sobre a existência do éter ${ }^{12}$, explora

\footnotetext{
${ }^{12}$ De acordo com Nersessian (1984, p. 65), "Maxwell sempre escolhe aquelas citações que fazem Faraday aparecer como se ele acreditasse no éter".
} 
a vertente da ação contígua construindo modelos mecânicos para o éter. Matéria imponderável, o éter é o mediador nas interações. Com os argumentos teóricos e experimentais a favor da unificação da óptica com o eletromagnetismo, o éter eletromagnético vai se confundir com o éter luminífero. Como mediador da interação, ele passa a ser o suporte para a propagação da onda eletromagnética e, desta forma, adquire outra ontologia: é o referencial a partir do qual é medida a velocidade de propagação da onda. É em relação a esse sentido que, em seu artigo de 1905, ao tecer argumentos contra o espaço/referencial absoluto, Einstein se opõe: "A introdução de um 'éter luminífero' revelar-se-á supérflua” (EINSTEIN, 1971, p. 48).

Essa idéia, entretanto, não convence imediatamente a todos ${ }^{13}$, principalmente a Lorentz, cuja formulação, concorrente com a de Einstein, comportava um éter estacionário. Mas, com a retirada do éter, um problema foi criado: sem o éter, mediador da ação entre as partículas, como é possível dar conta das interações em situações dinâmicas? Este é o problema levantado e enfrentado pela relatividade especial, como mostram, por exemplo, livros de Mecânica Analítica:

É evidente que a ação à distância nos moldes estritamente newtonianos é incompatível com a teoria especial da relatividade, porque envolve a propagação instantânea, isto é, com velocidade infinita, da interação entre as partículas. Para contornar essa dificuldade, poder-se-ia conceber uma ação à distância retardada, de tal modo que qualquer modificação no estado de uma partícula somente seria sentida por outra depois de transcorrido um tempo igual ao necessário para a luz cruzar a distância entre elas. Nesse caso a modificação do momento linear de uma partícula não se refletiria na mudança imediata do momento linear das outras, mas teria que haver um momento linear em trânsito de uma partícula para as outras a fim de assegurar a conservação do momento linear total. Isso indica que, [...] numa teoria relativística, as interações entre partículas têm que ser mediadas por campos locais dotados de propriedades mecânicas, tais como energia e momento linear. (LEMOS, 2004, p. 205, grifo nosso)

Mais adiante o autor continua:

Esse "teorema da ausência de interação" [...] estabelece de forma inequívoca que a implementação da lei de conservação da energia e do momento linear de um sistema de partículas em interação requer a introdução de outra entidade portadora de energia e momento, a saber, o campo mediador da interação. A interação

\footnotetext{
${ }^{13}$ É interessante observar que o próprio Einstein, depois de formular a teoria da relatividade geral, volta a defender o éter em 1920, mas com o significado de suporte de propagação da onda eletromagnética: "De acordo com a teoria da relatividade geral espaço sem éter é impensável; pois em tal espaço não só não existiria a propagação da luz, mas também nenhuma possibilidade de existência de padrões de espaço e tempo" (EINSTEIN, 1920, p. 3).
} 
O conceito de campo: polissemia nos manuais, significados ...

entre duas partículas afastadas deve ser interpretada como uma ação por contato de uma partícula sobre o campo, seguida de propagação do campo e, finalmente, ação por contato do campo sobre a outra partícula. (LEMOS, 2004, p. 207, grifo nosso)

Em situações dinâmicas, tal como a tratada - "qualquer modificação no estado de uma partícula", faz sentido, então, a expressão "campo armazena energia". Hewitt, que opta por uma definição contemporânea de campo, esclarece bastante bem a situação:

O campo elétrico ajuda-nos a compreender não apenas as forças entre corpos isolados, estacionários e eletrizados, mas também o que acontece quando as cargas se movimentam. Quando isso ocorre, seus movimentos são transmitidos aos corpos eletrizados vizinhos, na forma de uma perturbação do campo. As perturbações emanam dos corpos eletrizados que estão sendo acelerados, e se propagam com a rapidez da luz. Aprendemos que o campo elétrico é uma espécie de armazém de estocagem de energia, a energia pode ser transportada a grandes distâncias por um campo elétrico. (HEWITT', 2002, p. 381)

Com a nova ontologia - campo como mediador da interação entre partículas -, pode-se atribuir ao campo ações típicas de partículas, ações que causam tanta estranheza no reduto da Física clássica: interagir com outras partículas, armazenar energia e momento, além de preencher o espaço e ser suporte para a propagação de energia (como se verá adiante). Ironicamente, enquanto o eletromagnetismo sofre um processo de desmecanização em Maxwell (ABRANTES, 1998), o conceito de campo adquire, em tempos atuais, propriedades dinâmicas. Este é o legado deixado pela teoria da relatividade restrita. Segundo Nersessian,

[...] o campo não é mais o estado de algum tipo de matéria, mas está ontologicamente em par com a matéria. $\mathrm{Na}$ teoria especial, o campo não é somente indispensável para a descrição das ações eletromagnéticas, como com Maxwell e Lorentz, mas é também um elemento irredutível de descrição, da mesma forma que o conceito de matéria na mecânica newtoniana. Ele é independente da matéria e está livre para interagir com ela. O campo eletromagnético interage com a matéria recebendo energia e momento dela e transferindo essas quantidades para ela. A fim de que essas quantidades sejam conservadas, é necessário atribuir as mesmas propriedades dinâmicas de energia/massa, momento, e momento angular atribuída à matéria, para o campo eletromagnético. (NERSESSIAN, 1984, p. 134)

Ou, nas próprias palavras de Einstein (1920, p. 2): “O éter não existe mais. Os campos eletromagnéticos não são estados de um meio, e não estão ligados a qualquer mediador, mas eles são realidades independentes que não são redutíveis a qualquer outra coisa, exatamente como os átomos da matéria ponderável”. 
Krapas, S.; Da Silva, M. C.

\section{Campo se propaga, é suporte para a propagação de energia}

Com o campo definido como na seção anterior, não fica desprovido de sentido afirmar, tal como o faz Hewitt, que "a energia pode ser transportada a grandes distâncias por um campo elétrico" (2002, p. 381). Campo é suporte de propagação da energia, portanto pode transportar energia. Mas a liberdade da linguagem admite outras formas de expressão, tais como "propagação do campo", utilizada na última citação de Lemos.

Admissíveis em cursos avançados, expressões desse tipo introduzem obscuridades no Ensino Médio: “o campo elétrico, assim como a luz, se propaga no vácuo” (GASPAR, 2000b, p. 36), já que diz respeito à não simultaneidade dos eventos imposta pela relatividade restrita. $\mathrm{Na}$ Física clássica, entidades que têm a propriedade de se propagar são onda e partícula, e campo não é uma coisa nem outra. Expressões menos conflituosas são utilizadas por Tipler (1984, p. 604): "propagação da modificação do campo".

\section{Campo preenche o espaço}

Também adquire sentido afirmar que campo preenche o espaço:

Da mesma forma como o espaço ao redor de um planeta ou de outros corpos massivos está preenchido por um campo gravitacional, o espaço ao redor de cada corpo eletricamente carregado está também preenchido por um campo elétrico - uma espécie de aura que se estende através do espaço. (HEWITT, 2002, p. 380-381)

Talvez por reconhecer a estranheza da expressão, Guimarães e Fonte Boa preferem fazer uso de aspas: "seu quarto pode estar vazio de coisas; no entanto, está 'preenchido' de campo gravitacional" (GUIMARÃES e FONTE BOA, 2001b, p. 118).

Com o intuito de apresentar um resumo da análise realizada até aqui, construímos o quadro 1:

\begin{tabular}{|l|c|c|c|c|c|c|c|}
\hline & $\begin{array}{c}\text { Gaspar } \\
(2000 a, \\
\text { 2000b) }\end{array}$ & $\begin{array}{c}\text { Gonçalves } \\
\text { e Toscano } \\
(2003)\end{array}$ & $\begin{array}{c}\text { Guimarães e } \\
\text { Fonte Boa } \\
(2001 \mathrm{a}, 2001 \mathrm{~b})\end{array}$ & $\begin{array}{c}\text { Hewitt } \\
(2002)\end{array}$ & $\begin{array}{c}\text { Máximo e } \\
\text { Alvarenga } \\
(2002)\end{array}$ & $\begin{array}{c}\text { Ramalho, } \\
\text { Nicolau e } \\
\text { Toledo } \\
(1998)\end{array}$ & $\begin{array}{c}\text { Sampaio e } \\
\text { Calçada } \\
(2001)\end{array}$ \\
\hline espaço & $\mathrm{X}$ & $\mathrm{X}$ & $\mathrm{X}$ & $\mathrm{X}$ & $\mathrm{X}$ & $\mathrm{X}$ & \\
\hline vetor & $\mathrm{X}$ & $\mathrm{X}$ & $\mathrm{X}$ & $\mathrm{X}$ & $\mathrm{X}$ & $\mathrm{X}$ & $\mathrm{X}$ \\
\hline curvatura do espaço & & & $\mathrm{X}\left(^{*}\right)$ & $\mathrm{X}$ & & & \\
\hline $\begin{array}{l}\text { armazena energia } \\
\text { interage com partículas, } \\
\text { media a interação entre elas }\end{array}$ & $\mathrm{X}$ & $\mathrm{X}$ & $\mathrm{X}$ & $\mathrm{X}$ & $\mathrm{X}$ & & $\mathrm{X}$ \\
\hline $\begin{array}{l}\text { se propaga, é suporte } \\
\text { para a propagação de energia }\end{array}$ & $\mathrm{X}\left(^{*}\right)$ & & & $\mathrm{X}$ & & & \\
\hline preenche o espaço & & & $\mathrm{X}$ & $\mathrm{X}$ & & & $\mathrm{X}$ \\
\hline
\end{tabular}

$\left.{ }^{*}\right)$ Fora do corpo do texto

Quadro 1. Ocorrência dos diversos significados do termo campo nos sete livros didáticos do Ensino Médio. 


\section{Conclusões}

O termo campo já foi incorporado à linguagem de senso comum. É possível, por exemplo, utilizar trechos de desenhos animados nos quais aparece esse termo, quando o objetivo é investigar a psicogênese do conceito de campo (NARDI, 1991). Na maioria das vezes, o sentido é equivocado, de barreira de proteção, por exemplo. Guimarães e Fonte Boa apontam essa imprecisão:

De vez em quando, nos desenhos animados ou quadrinhos de ficção científica, vemos um personagem acionar 'um campo de forças'. Esse campo, em geral, se manifesta como uma 'barreira protetora', um 'escudo invisível e invulnerável', que impede, por exemplo, que a nave dele seja atingida pelos disparos das armas do inimigo. (GUIMARÃES e FONTE BOA, 2001b, p. 117)

Os manuais, no entanto, não têm contribuído para tornar o termo menos impreciso. A liberdade com que o utilizam é assimilada - implicitamente, é claro - pelos alunos, que chegam a usar expressões como "interação entre campos" para explicar fenômenos eletromagnéticos simples, como um motor elétrico. A idéia de que campos interagem ${ }^{14}$ pode ser reforçada por expressões como a utilizada por Gaspar (2000b, p. 198): “a Terra e a Lua, que interagem através de seus campos". Na verdade, o autor está se referindo à ação e reação entre a Lua e a Terra "intermediadas por um campo" (p. 198).

A partir da análise que realizamos, a que podemos creditar à polissemia encontrada nos manuais? Consideremos inicialmente os significados vetor e espaço. O intercâmbio de significados tem origens no passado, em expressões usadas por Maxwell e Lorentz. Conscientes dessa ambigüidade, Sampaio e Calçada (2001) chamam à atenção o fato de que campo não é espaço. Gaspar opta por usar termos distintos para os dois conceitos, mas, apesar do alerta, ele mesmo, na continuidade de seu texto, não mantém a distinção proposta. Se na linguagem escrita é difícil se desvencilhar das origens - Sampaio e Calçada o fazem -, mais difícil ainda é estabelecer controle sobre a linguagem oral: o usual entre, os físicos, é o intercâmbio de significados. É aceitável, pois, essa ambigüidade.

Em relação a campo como curvatura do espaço, é explícita a referência à Teoria da Relatividade Geral, em local destacado do corpo do texto, o que leva à relativização de sua importância na questão aqui tratada.

As outras acepções do termo - campo armažena energia; campo interage com particulas, media a interação entre partículas; campo se propaga, é suporte para a propagação; campo preenche o espaço - são próprias à linguagem da Física a partir da Teoria da Relatividade Restrita. Entendemos suas

\footnotetext{
${ }^{14}$ Vale acrescentar que essa expressão adquire sentido na Física relativística: "nós levamos em conta a possibilidade que o sistema consiste de dois ou mais campos que interagem. A completa densidade Lagrangiana consiste da soma das densidades Lagrangianas representando os campos livres mais termos que descrevem as interações entre campos”. (GOLDSTEIN, 1980, p. 575)
} 
Krapas, S.; Da Silva, M. C.

inclusões no livro didático como uma certa "contaminação" do sentido "relativístico" sobre o sentido "clássico" de campo ${ }^{15}$. Vamos defender que esta contaminação é uma forma velada de introdução da Física moderna nos manuais ${ }^{16}$.

Chama a atenção, nos manuais, a alta ocorrência de campo como mediador da interação. A razão pode estar no fato de que essa terminologia já era usada antes do advento da Teoria da Relatividade Restrita. Partidário da ação mediada, Lorentz (1952) atribui ao termo propriedades do éter ${ }^{17}$ : "podemos calcular a ação do campo sobre ele [um elétron]” (p. 15). As novidades trazidas por Einstein implicaram mudança ontológica do conceito de campo ${ }^{18}$, mas a linguagem se manteve. Essa continuidade na linguagem pode ter facilitado, àquela época, a tarefa dos livros didáticos de se adaptarem a novidades. Resumindo, em parte podemos atribuir a polissemia a resquícios de linguagem relacionados a componentes de teorias já abandonadas no decorrer da história da ciência (campo como matéria imponderável, mediador das interações, como em Lorentz), resquícios de linguagem que se confundem com os relacionados a componentes de teorias em vigência (campo como categoria ontológica a par com a matéria, mediador das interações na Teoria da Relatividade Restrita).

Mas, como entender que isso constitui uma forma velada de introduzir a Física moderna nos livros didáticos? Tradicionalmente, ao tratar seus conteúdos, os manuais desconsideram sua história. De fato, alerta Kuhn (1982, p. 175):

[...] sendo os manuais veículos pedagógicos destinados a perpetuar a ciência normal, devem ser parcial ou totalmente reescritos toda vez que a linguagem, a estrutura dos problemas ou as normas da ciência normal se modifiquem. Em suma, precisam ser reescritos imediatamente após cada revolução científica e, uma vez reescritos, dissimulam inevitavelmente não só o papel desempenhado, mas também a própria existência das revoluções que os produziram.

Chevallard vai mais longe ${ }^{19}$ :

\footnotetext{
${ }^{15}$ Em manuais antigos, como Ganot (1884) e Gouvêa, onde o éter ainda não havia sido excluído, essas acepções não existem. A data de publicação de Gouvêa é estimada por Sampaio (2004) em 1902, em sua primeira edição, e em 1920, na sétima edição.

${ }^{16}$ Essa introdução não deve ser confundida com o movimento atual de reformulação curricular de introdução da Física moderna e contemporânea no Ensino Médio (OSTERMANN e MOREIRA, 2000).

${ }^{17}$ Para Lorentz, o éter está separado da matéria ordinária, inclusive não obedece à terceira lei de Newton: "Reconhecidamente esta concepção [a do éter] violaria a lei de ação e reação - desde que temos razão para dizer que o éter exerce forças sobre matéria ponderável - mas, até onde vejo, não há nada que obrigue a promover aquela li a uma lei fundamental de validade ilimitada" (LORENTZ apud NERSESSIAN, 1984, p. 104).

${ }^{18}$ Com Nersessian discordamos de Hirosige: "podemos ver [em Lorentz] o moderno conceito de campo eletromagnético definitivamente estabelecido" (HIROSIGE apud NERSESSIAN, 1984, p. 113).

${ }^{19}$ Paradoxalmente, as demandas atuais da noosfera - esfera onde se pensa o funcionamento didático - sobre o sistema de ensino, na figura dos PCN, por exemplo, vão na direção de introduzir a história da ciência noensino de ciências.
} 
O conceito de campo: polissemia nos manuais, significados ...

O saber que a transposição didática produz será, portanto, exilado de suas origens e separado de sua produção histórica na esfera do saber sábio, legitimando-se, enquanto saber ensinado, como algo que não é de nenhum tempo nem de nenhum lugar, e não se legitimando mediante recurso da autoridade de um produtor, qualquer que ele seja. (CHEVALLARD, 1998, p. 18) funcional ${ }^{20}$ :

$\mathrm{E}$ as razões pelas quais o saber ensinado se distingue do saber sábio são de ordem

Porque o funcionamento didático do saber é distinto do funcionamento acadêmico, porque há dois regimes do saber, interrelacionados, mas não superpostos. (CHEVALLARD, 1998, p. 25)

Seu funcionamento [do sistema didático] ... supõe que a "matéria" (professor, alunos e saber) que virá a ocupar cada um dos lugares, satisfaça certos requisitos didáticos específicos. Para que o ensino de um determinado elemento de saber seja meramente possível, esse elemento deverá sofrer certas deformações, que o tornem apto para ser ensinado. O saber-tal-como-é-ensinado, o saber ensinado, é necessariamente distinto do saber-inicialmentedesignado-como-o-saber-que-deve-ser-ensinado, o saber a ensinar. Este é o terrível segredo que o conceito de transposição didática põe em perigo. (p. 17-18, grifos nossos)

A situação em que se encontra o ensino do conceito de campo parece bem descrita pelo funcionamento do sistema didático segundo Chevallard. Requisitos didáticos historicamente situados - e que vale a pena serem investigados em detalhe - transformaram o saber sábio de forma que não é possível identificar nos manuais a revolução operada pela Teoria da Relatividade Restrita. Num processo de sucessivas adaptações (feitas nem sempre de forma consciente pelos autores dos livros) a linguagem dos manuais vai lentamente se impregnando da linguagem da Física em vigência, sem que isso seja acompanhado de mudança ontológica. Assim, o saber transformado ficou necessariamente "exilado de suas origens e separado de sua produção histórica na esfera do saber sábio” (CHEVALLARD, 1998, p. 18).

\footnotetext{
${ }^{20}$ Embora diferentes, os argumentos de Kuhn (1982) para se opor à introdução da história da ciência no ensino são também de ordem funcional: "Grande parte da imagem que cientistas e leigos têm da atividade científica criadora provém de uma fonte autoritária que disfarça sistematicamente - em parte devido a razões funcionais importantes - a existência e o significado das revoluções científicas” (p. 174).
} 
Krapas, S.; Da Silva, M. C.

Com este trabalho pretendemos apontar para o fato de que, no que diz respeito ao conceito de campo, o saber ensinado, polissêmico porque exilado de suas origens, pode acarretar sérios problemas de aprendizagem. Nesse sentido, vale destacar o alerta do próprio Chevallard, sobre as transformações/deformações pelas quais passam o saber sábio:

[...] o saber ensinado - o saber tratado no interior do sistema [de ensino] - deve ser visto, pelos mesmos "acadêmicos", como suficientemente próximo do saber sábio a fim de não provocar a desautorização dos matemáticos [acadêmicos em pauta], o que minaria a legitimidade do projeto social, socialmente aceito e sustentado, de seu ensino. (CHEVALLARD, 1998, p. 30)

No caso estudado, no entanto, acontece que a maioria dos físicos (acadêmicos em pauta) não desautoriza a forma historicamente descontextualizada com que o conceito de campo é introduzido no Ensino Médio. Na verdade, essa deve ser a forma adotada por muitos deles no ensino universitário, se considerarmos o estudo de Pocovi e Finley (2003) sobre livros didáticos de ensino superior populares no mundo.

Uma das metas do presente trabalho, assim como de muitos aqui citados, é despertar a comunidade para essa problemática. Outra é oferecer subsídios para o planejamento (DA SILVA E KRAPAS, 2007) e implementação de inovações didáticas. 
O conceito de campo: polissemia nos manuais, significados ...

\section{Referências}

ABRANTES, P. Imagens de natureza, imagens de ciência. Campinas: Papirus, 1998.

ARONS, A. B. Teaching introductory Physics. New York: John Wiley \& Sons, 1997.

ASSIS, A. K. T. Interações na Física - ação à distância versus ação por contato. In: SILVA, C. C. Estudos de História e Filosofia das Ciências. São Paulo: Livraria da Física, 2006. p. 87-102.

ATTWOOD, S. S. Electric and magnetic fields. London: Chapman \& Hall, 1941.

BERKSON, W. Las teorías de los campos de fuerza: desde Faraday hasta Einstein. Madrid: Alianza Editorial, 1981.

BRASIL. Ministério da Educação. Portaria nº 366, de 31 de janeiro de 2006. Diário Oficial da União, edição no 23, 01 fev. 2006.

CHAVES, A. Física. Eletromagnetismo. Rio de Janeiro: Reichmann \& Affonso, 2001.

CHEVALLARD, Y. La transposición didáctica. Buenos Aires: Aique, 1998.

CROWTHER, J. A. A manual of Physics. London: Henry Frowde and Hodder \& Stoughton, 1921.

CUSHING, J. T. Philosophical concepts in Physics. Cambridge: Cambridge University Press, 1998.

DA SILVA, M.; KRAPAS, S. Controvérsia ação à distância/ação mediada: abordagens didáticas para o ensino das interações físicas. Revista Brasileira de Ensino de Física, São Paulo, v. 29, n. 3, p. 471-479, 2007.

DOMÍNGUEZ, M.; MOREIRA, M. A. Significados atribuídos aos conceitos de campo elétrico e potencial elétrico por estudantes de física geral. Revista Brasileira de Ensino de Física, São Paulo, n. 10, p. 67-82, 1988.

EINSTEIN, A. Sobre a electrodinâmica dos corpos em movimento. In: LORENTZ, H. et al. (Orgs.). O princípio da relatividade. Coimbra: Fundação Calouste Gulbenkian, 1971. p. 47-86.

Ether and the Theory of Relativity. Conferência proferida em 5 de maio de 1920, na Universidade de Leyden. Disponível em: <http://www.cfpf.org.uk/articles/ scientists/einstein.html>. Acesso em: 10 jan. 2005.

FURIÓ, C.; GUISASOLA, J. La enseñanza del concepto de campo elérico basada em um modelo de aprendizaje como investigación orientada. Enseñanza de las Ciencias, Barcelona, v. 19, n. 2, p. 319-334, 2001.

.; ___ Deficiencias epistemológicas en la enseñanza habitual de los conceptos de campo y potencial eléctrico. Enseñanza de las Ciencias, Barcelona, v. 15, n. 2, p. 259-271, 1997. 
Krapas, S.; Da Silva, M. C.

GALILI, I. Mechanics background influences student' conceptions in eletromagnetism.

International Journal of Science Education, Londres, v. 17, n. 3, p. 371-387, 1995.

GANOT, A. Traité Élémentaire de Physique. Paris: Daguin/Pierre Adolphe, 1884.

GASPAR, A. Física 1: mecânica. São Paulo: Editora Ática, 2000a.

Física 3: eletromagnetismo e Física moderna. São Paulo: Editora Ática, 2000b.

GARDELLI, D. Concepções de interação física: subsídios para uma abordagem histórica do assunto. 2004. 119f. Dissertação (Mestrado) - Universidade de São Paulo, São Paulo, 2004.

GOLDSTEIN, H. Classical mechanics. Reading: Addison-Wesley Publishing Company, 1980.

GONÇALVES, A.; TOSCANO, C. Física para o Ensino Médio. São Paulo:

Scipione, 2003.

GOUVÊA, N. Lições de Physica. Rio de Janeiro: Francisco Alves, [s.d.].

GUIMARÃES, L. A.; FONTE BOA, M. Mecânica. Niterói: Futura, 2001a.

.; __ Eletricidade e ondas. Niterói: Futura, 2001b.

HALLIDAY, D.; RESNICK, R. Fundamentos de Física: eletromagnetismo. Rio de Janeiro: Livros Técnicos e Científicos, 1991.

HARNWELL, G. P. Principles of electricity and electromagnetism. New York: McGraw-Hill, 1938.

HEWITT, P. G. Física conceitual. Porto Alegre: Artmed Editora, 2002.

KRAPAS, S.; DA SILVA, M. C. Forças que atuam à distância: representações em livros didáticos do Ensino Médio e a história da ciência. In: ENCUENTRO IBEROAMERICANO SOBRE INVESTIGACIÓN BÁSICA EN EDUCACIÓN EN CIENCIAS, 2., 2004, Espanha. Resumenes .... Burgos, 2004. p. 17.

.; et al. Prego voador: um desafio para estudantes de eletromagnetismo. Revista

Brasileira de Ensino de Física, São Paulo, v. 27, n. 4, p. 1-4, 2005.

KUHN, T. S. A estrutura das revoluções científicas. São Paulo: Perspectiva, 1982.

LEMOS, N. A. Mecânica analítica. São Paulo: Editora Livraria da Física, 2004.

LORENTZ, H. A. Theory of electrons. New York: Dover, 1952.

mÁximo, A.; ALVARENGA, B. Curso de Física volume 3. São Paulo: Editora Scipione, 2002.

MAXWELL, J. C. A treatise on electricity and magnetism.New York: Dover, 1954a. v. 1. A treatise on electricity and magnetism. New York: Dover, 1954b. v. 2. 
O conceito de campo: polissemia nos manuais, significados ...

On Faraday's lines of force. In: NIVEN, W. D. The scientific papers of James Clerk Maxwell. New York: Dover, 1952a. p. 155-229. v. 1.

On physical lines of force. In: NIVEN, W. D. The scientific papers of James Clerk Maxwell. New York: Dover, 1952b. p. 451-513. v. 1.

A dynamical theory of electromagnetic field. In: NIVEN, W. D. The scientific papers of James Clerk Maxwell. New York: Dover, 1952c. p. 526-597. v. 1.

NARDI, R. Campo de força: subsídios históricos e psicogenéticos para a construção do ensino desse conceito. São Paulo: Universidade de São Paulo, 1991. (Textos de Pesquisa n. 5).

NERSESSIAN, N. J. Faraday to Einstein: constructing meaning in scientific theories. Dordrecht: Martinus Nijhoff Publishers, 1984.

NUSSENZVEIG, H. M. Curso de Física básica: eletromagnetismo. São Paulo: Edgard Blücher, 1997.

Curso de Física básica: mecânica. São Paulo: Edgard Blücher, 1992.

OSTERMANN, F.; MOREIRA, M. A. Uma revisão bibliográfica sobre a área de pesquisa "Física Moderna e Contemporânea no Ensino Médio". Investigações em Ensino de Ciências, Porto Alegre, v. 5, n. 1, p. 23-48, 2000.

POCOVI, M. C.; FINLEY, F. N. Historical evolution of the field view and textbook accounts. Science \& Education, Dordrecht, Holanda, v. 12, n. 4, p. 387-396, 2003.

POYNTING, J. H.; THOMSON, J. J. Eletricity and magnetism: stactic electricity and magnetism. London: Charles Griffin, 1914. (Parte I e II).

RAMAlHO, F.; NICOLAU, G. F. E.; TOLEDO, P. A. Os Fundamentos da Física. São Paulo: Editora Moderna, 1998.

SAMPAIO, G.M. D. História do ensino de Física no Colégio Pedro II de 1838 até 1925. 2004. 172f. Dissertação (Mestrado) - Universidade Federal do Rio de Janeiro, Rio de Janeiro, 2004.

SAMPAIO, J. L.; CALÇADA, C. S. Universo da física, 3: ondulatória, eletromagnetismo, Física moderna. São Paulo: Atual, 2001.

THE OXFORD ENGLISH DICTIONARY. Oxford: Oxford University Press, 1961.

TIPLER, P. A. Física/2a. Rio de Janeiro: Guanabara Dois, 1984.

WHITTAKER, E. A history of theories of aether and electricity. Londres: Thomas Nelson and Sons, 1958. v. 1.

Artigo recebido em fevereiro de 2007 e aceito em junho de 2007. 
